\title{
Muscular imbalance and shoulder pain in volleyball attackers
}

\author{
A Kugler, M Krüger-Franke, S Reininger, H-H Trouillier, B Rosemeyer
}

\begin{abstract}
Objective-In overhead sports such as volleyball, baseball, or tennis shoulder problems are very common. The aim of this study was to identify features which may correlate with shoulder problems in volleyball attackers.

Methods-30 competitive volleyball attackers (mean age 25 years) were included in the study; 15 were suffering from shoulder pain and 15 had no history of shoulder pain. The results were compared with those of a control group of 15 recreational athletes without any overhead sports activities.

Results-Volleyball attackers have a different muscular and capsular pattern at the playing shoulder compared to the opposite shoulder. Their playing shoulder is depressed, the scapula lateralised, and the dorsal muscles and the posterior and inferior part of the shoulder capsule shortened. These differences were of more significance in volleyball attackers with shoulder pain than in volleyball players without shoulder pain. In contrast to recreational athletes without any overhead sports activity, there were no significant difference in the comparison of the two shoulders. The histories, clinical and sonographic findings did not reveal further typical features for volleyball attackers with shoulder pain.

Conclusions-Muscular balance of the shoulder girdle is very important in this sport. It is therefore imperative to include adequate stretching and muscular training programme for the prevention, as weli as for therapy, of shoulder pain in volleyball attackers.
\end{abstract}

(Br f Sports Med 1996;30:256-259)

Key terms: volleyball; overhead sports; shoulder pain; muscular imbalance

Staatliche

Orthopädische Klinik, Harlachinger Strasse 51,81547 München, Germany

A Kugler

M Krüger-Franke

$S$ Reininger

$\mathrm{H}-\mathrm{H}$ Trouillier

B Rosemeyer

Correspondence to: Dr A Kugler.

Accepted for publication 14 March 1996. the hit downwards on the ball so that the ball cannot be returned. This specialisation causes uniform repetitive loads for the players.
Table 1 Anthropometic data (mean and standard deviation) of the volleyball attackers with shoulder pain (group 1), volleyball attackers without shoulder pain (group II), and recreational athletes (group III). Values are means (SD).

\begin{tabular}{llll}
\hline Group & $I(n=15)$ & $I I(n=15)$ & $I I I(n=15)$ \\
\hline Age (years) & $24.8(2.9)$ & $25.1(3.1)$ & $24.0(3.1)$ \\
Weight (kg) & $74.2(11.9)$ & $76.6(9.0)$ & $74.5(13.3)$ \\
Height (cm) & $182.7(9.0)$ & $183.9(7.9)$ & $178.6(9.4)$ \\
Practice/week (h) & $5.7(2.7)$ & $5.5(1.9)$ & - \\
Career in years & $9.5(3.6)$ & $11.0(3.0)$ & - \\
\hline
\end{tabular}

A highly skilled volleyball attacker, for example, with $16-20$ hours weekly practice time, spikes about 40000 times a year. ${ }^{1}$ This results in a higher risk for developing shoulder pain for the attacker, which is also seen in other overhead sports including baseball or tennis, ${ }^{2-6}$ as reported by many investigators.

The purpose of this study was to inspect the clinical and sonographic findings, as well as to analyse the players' history for special features.

\section{Methods}

During the $1992 / 93$ season, 15 volleyball attackers (10 male, five female) with shoulder pain (group 1), 15 volleyball attackers (12 male, three female) without any episodes of shoulder pain (group II), and 15 recreational athletes (12 male, three female) without any shoulder problems and not participating in any overhead sports (group III) were included in this study. The groups were comparable in age, weight, and height (table 1).

No overhead work was done by any participants of this study .

The spiking arm was also the dominating arm in 14 players in group I and II.

All attackers were third national league players with comparable practice time, playing career, playing parts, and positions. The examination was performed at least $2 \mathrm{~d}$ after the last practice [group I: 3.1 (SD 2.2) days; group II: 4.1(3.0) days].

All participants of this study were interviewed with a standardised questionnaire including questions about the onset and cause of the shoulder pain, previous injuries, localisation of the pain, painful movements, previous treatment, and stretching time.

A standardised clinical examination was performed according to Brunner and Habermeyer ${ }^{7}$ and Constant, ${ }^{8}$ concentrating specially on shoulder depression, tender points, crepitation, upper arm girth, arm length, active and passive range of motion, and muscle strength. Several shoulder tests were performed including the $0^{\circ}$ abduction test, $90^{\circ}$ supraspinatus 


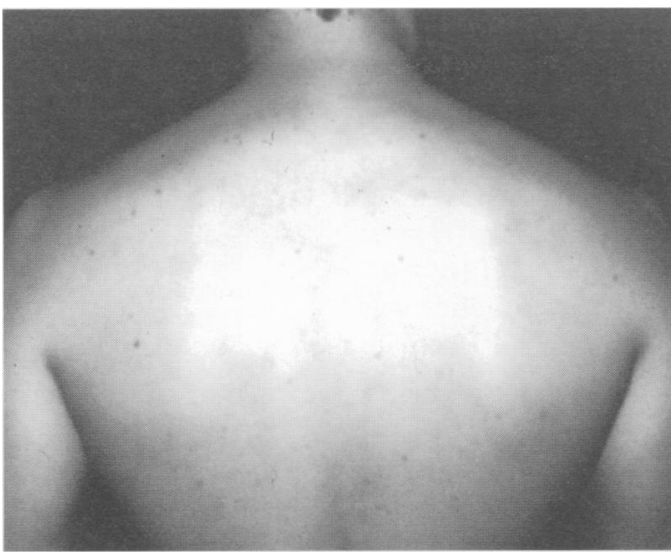

Figure 1 In a standing position the distance between the spinous process of thoracic spine (T5) and the medial border of the scapula is measured horizontally with arms loose beside the body.

test in internal and external rotation, resisted internal and external rotation with $90^{\circ}$ flexed elbow beside the trunk, the impingement test according to Neer, the Yergason test, and the palm-up test. Stability was ensured by the drawer test and the apprehension test at $60^{\circ}$, $90^{\circ}$, and $120^{\circ}$. The acromioclavicular joint was also examined.

Additional measurements around the shoulder girdle were taken, measuring the distance between the spinous process of thoracal spine (T5) and the medial border of the scapula with arms hanging loosely beside the body (fig 1), the distance from the lateral epicondyle to the acromion of the opposite side by maximum horizontal adduction (fig 2), the distance from the tip of the middle finger to the lumbar spine (L5) by maximum internal rotation of the shoulder up the back (fig 3), and the distance from the tip of the middle finger to the cervical spine (C7) behind the neck (fig 4).

As an indicator of general band laxity, the flexibility of the metacarpophalangeal joints I and II-V were measured, as well as the flexibility of the hamstrings and the rectus femoris muscle. ${ }^{9-10}$

Ultrasound examinations were performed with a 7.5 MHZ linear scanner (Siemens Sonoline) according to Hedtmann and Fett. ${ }^{11}$ Stability was ensured by the drawer test under sonographic control. ${ }^{1213}$

Statistical analysis was performed for all data using the Wilcoxon rank sum test. The $\alpha$ level was fixed at 0.05 for significance $(P<0.05)$. Values are given as mean(SD).

\section{Results}

All players reported only the playing shoulder to be painful. Pain was scored 5.1(1.4) on the visual analogue scale and lasted an average time of $2.7(2.7)$ years.

The cause for the pain was either "unknown" $(n=8)$ or from "spiking a ball without warming up" $(n=7)$.

Nine players complained about pain during and after playing, three only during playing, and the remaining three players reported permanent pain. Serving $(n=11)$ and spiking $(n=14)$ produced new pain sensations.

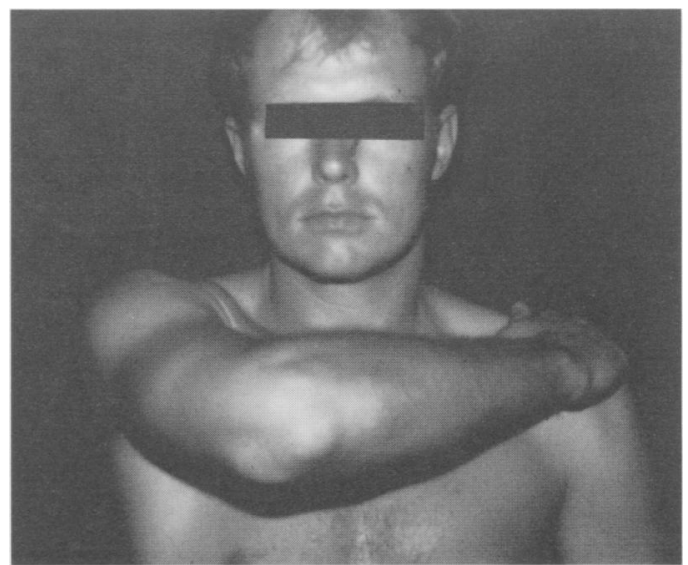

Figure 2 In a standing position the distance from the epicondyle radii to the acromion of the opposite side should be minimised by maximum horizontal adduction in $90^{\circ}$ of elevation.

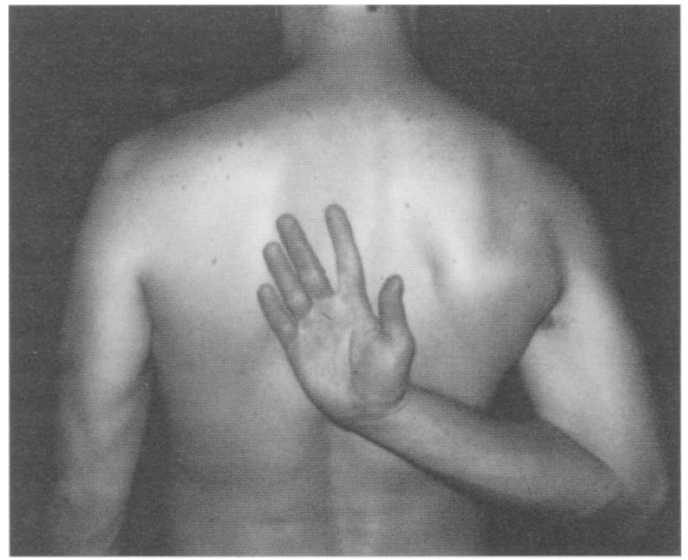

Figure 3 In a standing position the maximum distance from the tip of the middle finger to the lumbar spine (L5) by maximum internal rotation of the shoulder up the back is measured.

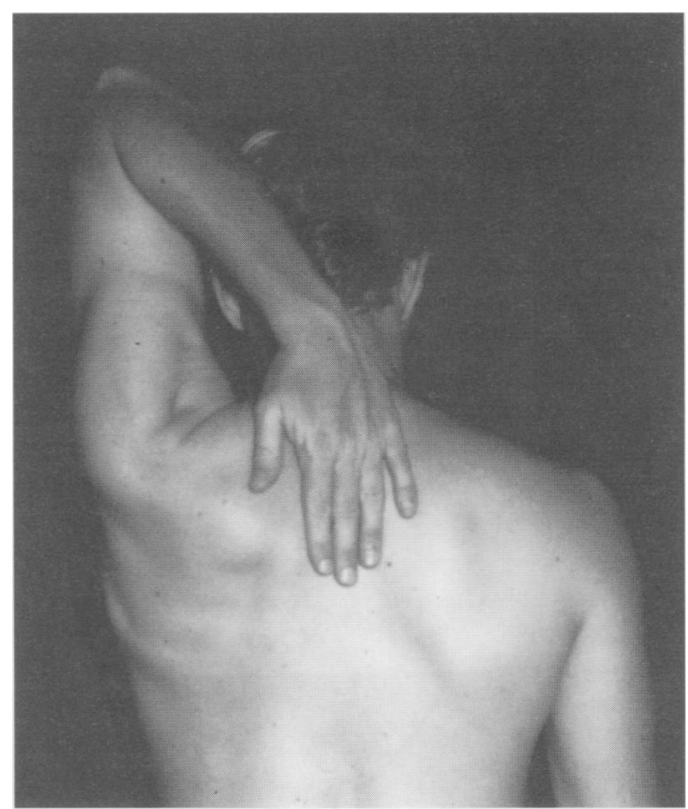

Figure 4 In a standing position the maximum distance from the tip of the middle finger to the cervical spine (C7) behind the neck is evaluated.

Sleeping on the playing shoulder $(n=11)$, bearing heavy loads $(n=10)$, or overhead activities $(n=8)$ were also reported to be painful. 
The localisation of the pain was lateral to the greater tuberosity $(n=8)$, at origin of the delta muscle $(n=3)$, in area of the anterior capsule $(n=2)$, or in the area of the long biceps tendon $(n=2)$.

A physician was not consulted by any player. The players used increased stretching $(n=5)$ and warming ointments for pain relief $(n=4)$.

The average stretching time per practice was 6.5(4.4) $\mathrm{min}$ in group I and 9.5(3.9) $\mathrm{min}$ in group II.

In all 30 players depression of the playing shoulder by 1-3 cm was evident, and in two players from group I and II there was also atrophy of the infraspinatus muscle of the playing shoulder; no shoulder depression could be found in the 15 recreational athletes.

The tone of the paravertebral muscles of the cervical spine and the trapezius was increased in nine players from group I, six players from group II, and four sportsmen from group III.

Crepitus of the playing shoulder was evident in 24 players (group I: $\mathrm{n}=14$; group II: $\mathrm{n}=10$ ) and in 10 recreational athletes.

There was no significant difference in flexibility of the metacarpophalangeal joints between the two hands and among the groups Flexibility of the hamstrings and the rectus femoris muscle were also comparable.

Upper arm girth in the playing arm was increased by about one $\mathrm{cm}$ in all groups.

In group I, the tender points were the origin of supraspinatus muscle $(n=5)$, the bicipital groove $(n=4)$, and the subacromial space $(n=4)$.

The active and passive range of motion was not restricted in any group and was comparable with the opposite side and among the various groups.

Pain was reported on active anteversion beyond $160^{\circ}(n=10)$ and or: active abduction beyond $140^{\circ}(n=4)$. Passive motion was pain-free.

The shoulder tests revealed positive results for four players in the $0^{\circ}$ abduction test, for

Figure 5 Distance and difference in the distance from the epicondyle radii to the acromion of the opposite side on maximum horizontal adduction (fig 2) in group I (volleyball attackers with shoulder pain), in group II (volleyball attackers without shoulder pain, and in group III (recreational athletes).

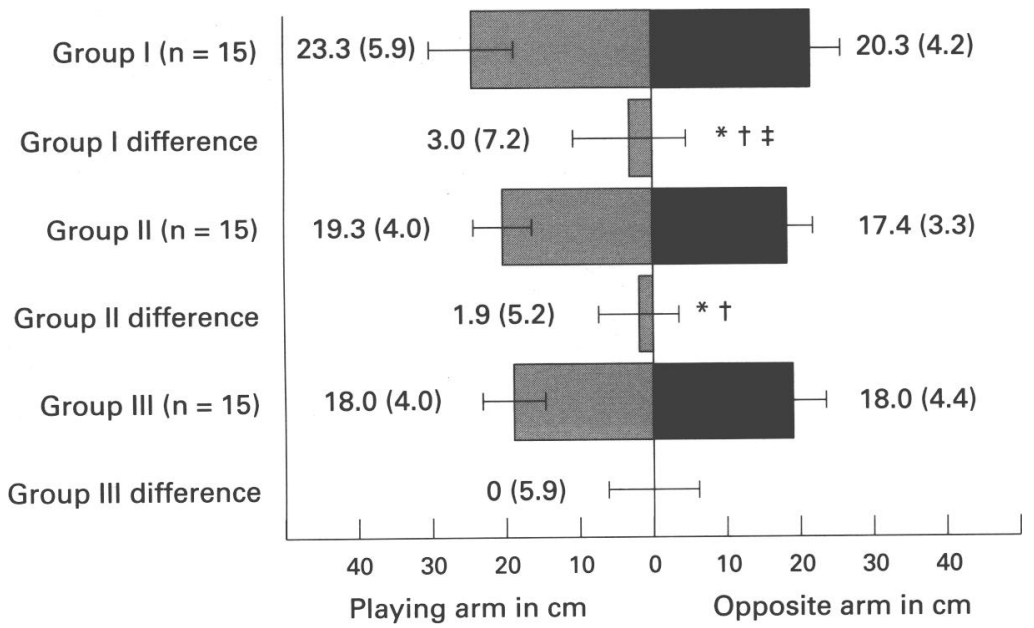

* Significant difference between playing shoulder and opposite shoulder; tsignificant difference v group III; $¥$ significant difference v group II.
Table 2 Results of the various arm/shoulder tests in the three groups

\begin{tabular}{|c|c|c|c|c|}
\hline \multirow{4}{*}{$\begin{array}{l}\text { Test } \\
\text { I }\end{array}$} & \multirow{5}{*}{$\begin{array}{l}\text { Playing arm } \\
\text { Non-playing } \\
\text { Difference }\end{array}$} & \multicolumn{3}{|l|}{ Group } \\
\hline & & $I(n=15)$ & II $(n=15)$ & $I I I(n=15)$ \\
\hline & & $8.4 \pm(1.1)$ & $8.7 \pm(1.9)$ & $8.6 \pm(1.9)$ \\
\hline & & $7.4 \pm(0.8)$ & $7.8 \pm(1.1)$ & $8.4 \pm(1.7)$ \\
\hline & & $1.0 \pm(1.4)$ & $0.9 \pm(2.2)$ & $0.2 \pm(2.5)$ \\
\hline \multirow[t]{3}{*}{ II } & Playing arm & $13.0 \pm(4.7)$ & $13.3 \pm(4.0)$ & $11.6 \pm(3.6)$ \\
\hline & Non-playing & $14.0 \pm(4.5)$ & $13.9 \pm(2.9)$ & $11.9 \pm(3.0)$ \\
\hline & Difference & $1.0 \pm(6.5)$ & $0.6 \pm(4.9)$ & $0.3 \pm(4.7)$ \\
\hline \multirow[t]{3}{*}{ III } & Playing arm & $30.3 \pm(8.4)$ & $38.2 \pm(8.7)$ & $34.0 \pm(7.4)$ \\
\hline & Non-playing & $36.8 \pm(7.0)$ & $38.5 \pm 7.5)$ & $38.9 \pm(7.0)$ \\
\hline & Difference & $6.5 \pm(10.9)$ & $0.3 \pm(11.5)$ & $4.9 \pm(10.2)$ \\
\hline
\end{tabular}

I: Distance and differences in the distances between the spinous process of thoracic spine (T5) and the medial border of the scapula (fig 1). Significant differences: difference between group I and II; difference between group II and III; difference spiking/ non-spiking shoulder in group I and II. II: Distance and differences in the distances from the tip of the middle finger to the lumbar spine $(5 \%)$ by maximal internal rotation of the shoulder up the back (fig 3). Significant differences: difference between group I and II; difference spiking/non-spiking shoulder in group I and II. III: Distance and differences in the distances from the tip of the middle finger to the cervical spine (C7) behind the neck (fig 4).

Group I (volleyball attackers with shoulder pain), Group II (volleyball attackers without shoulder pain, Group III (recreational athletes).

eight players in the $90^{\circ}$ supraspinatus test, for three players in the impingement test, for two players in the palm-up test, and for five players in the apprehension test. Resisted external (internal) rotation was painful in seven (four) players.

The difference in the distance from the lateral epicondyle to the acromion of the opposite side on maximum horizontal adduction (fig 2) was significantly increased for the playing shoulder in volleyball attackers and between all groups (fig 5).

The distance between the spinous process of thoracic spine (T5) and the medial border of the scapula (fig 1) was significantly widened on the playing shoulder in groups I and II. There was also a significant difference in both the playing shoulder and the opposite shoulder for volleyball attackers as opposed to recreational athletes, and for attackers with shoulder pain versus attackers without shoulder pain (table 2).

Measurements of the distance from the tip of the middle finger to the lumbar spine (L5) on maximum internal rotation of the shoulder up the back (fig 3) and the distance from the tip of the middle finger to the cervical spine (C7) behind the neck (fig 4) are shown in table 2.

Ultrasound examination revealed hyperechogenic areas at the origin of the supraspinatus tendon $(n=9)$, effusion around the biceps tendon $(n=8)$, and a bursitis $(n=9)$. In addition ventral instability was obvious in six players and dorsal instability in three players. A Hill Sachs lesion could not be found.

\section{Discussion}

In overhead sports shoulder problems are very common, ${ }^{3614}$ is predominantly in highly skilled sportsmen, because of the intense practice, short recreational time, high intensity, and repetitive loads caused by specialisation on certain tasks in the game, for example pitching for the baseball pitcher. ${ }^{14}$ The clinical findings vary considerably, and include instability, 
impingement, irritation of the biceps tendon, irritation of the rotator cuff, or subscapular neuropathy. ${ }^{4-51416}$ Our findings indicated considerable differences, without revealing any typical pattern.

A highly skilled volleyball player attacks about 40000 times a year. The impact occurs in an anteversion of about $170^{\circ}$ to $140^{\circ}$ in neutral rotation. The speed of the hand at this moment is approximately $13.1 \mathrm{~m} \mathrm{~s}^{-1}$ and accelerates the ball to velocities of up to $120 \mathrm{~km} \mathrm{~h}^{-1}$. Only $19.1 \%$ of this velocity originates in the glenohumeral joint. ${ }^{1}$ After the impact, the movement of the arm decelerates. This results in the production of dynamic eccentric forces at the posterior shoulder girdle musculature and the biceps. ${ }^{17} \mathrm{~A}$ change in one of the components of the shoulder girdle leads to a complete change in shoulder motion.

The orientation of the scapula is predicted in the upright position mainly from the length of the trapezius and levator scapulae muscles, and to a lesser extent from the length of the rhomboids and serratus anterior muscle. Muscle tone, however, does not play an important role. ${ }^{18}$ In recreational athletes we found symmetry between the two shoulders in all the measured variables. As in tennis or baseball players, volleyball players also have a depressed playing shoulder. This leads to a narrowed subacromial space in the upright position. ${ }^{614}$ The scapula of the playing shoulder was significantly lateralised in group I and II, without any scapular winging, suggesting a lengthening of the trapezius and rhomboid muscles.

The increased distance from the epicondyle of the playing arm to the acromion of the opposite side in maximum horizontal adduction can be interpreted as due to a shortened dorsal capsule of the playing shoulder. This difference was most marked in players with shoulder pain.

The distance from the tip of the middle finger to the lumbar spine (L5) on maximum internal rotation of the shoulder up the back was maximal on the playing shoulder in players with shoulder pain, suggesting a diminished ability to stretch the dorsal muscles.

The difference in the distance from the tip of the middle finger to the cervical spine (C7) behind the neck was not as noticeable. Therefore the inferior capsule does not appear to be affected in the playing shoulder-with or without pain.

The results show that both the muscles and the joint capsule of the playing shoulder in volleyball players are different from their non-playing shoulder. This is in contrast to the symmetry found in recreational athletes without overhead activities. The changes were most significant in volleyball attackers with shoulder pain.

This imbalance may lead to a disturbed movement pattern at the playing shoulder in volleyball attackers. It is conceivable that, if this imbalance has passed a certain level, the secondary changes that appear may be the cause of the shoulder pain.

A possible explanation might be that the tightened posterior and inferior structures, combined with a shoulder depression and a lateralisation of the scapula, lead to a disturbance of the gliding and rolling motion of the humeral head, thereby causing pain.

A biomechanical study which mimics this situation would give us improved insight into the mechanism of this alteration and warrants further investigation.

Although the exact mechanism of these alterations is not completely clear, our recommendation to volleyball players without shoulder pain-and especially to those with shoulder pain-is to stretch the shortened muscles and to strengthen the scapular fixation muscles. In addition, the technique of attacking should be optimised to use the shoulder muscles in an efficient manner. ${ }^{19}$ Many descriptive programmes are available to improve muscular function of the shoulder joint. ${ }^{1420-21}$ We feel that this is a practical approach to treatment, as well as a good preventive measure for shoulder pain in volleyball attackers.

1 Dübotzky V, Leistner $M$. Volleyball. In: Ballreich $R$ Kuhlow-Ballreich A, eds. Biomechanik der Sportarten: Bd 3: Biomechanik der Sportspiele, vol 2. Stuttgart: Enke Verlag 1992:72-123.

2 Benett GE. Shoulder and elbow lesions of professional baseball pitcher. $\mathscr{f} A M A$ 1941;117:510-15.

3 Gohlke F, Lippert MJ, Keck O. Instabilität und Impingement an der Schulter des Leistungssportler mit Überkopfment an der Schulter des Leistungssportler mit

4 Hawkins RJ, Kennedy JC. Impingement syndrom in athletes. Am 7 Sports Med 1980;8:151-8.

5 Jerosch J, Castro WHM, Sons HU. Das sekundäre ImpingementSyndrom beim Sportler. Sportverl Sportschad 1990;4 $180-5$

6 Priest JD, Nagel DA. Tennis shoulder. Am $f$ Sports Med 1976;4:28-42.

7 Brunner U, Habermeyer P. Die klinische Untersuchung der Schulter. In: Habermeyer P, Krueger P, Schweiberer L, eds Schulterchirurgie. Urban und Schwarzenberger, 1990:35.

8 Constant CR. Schulterfunktionsbeurteilung. Orthopäde 1991;20:289-94.

9 Munzinger U, De St Jon M, Conrad R, Ruef A. Das femoropatelläre Schmerzsyndrom im Sport. Der Chirurg 1988; 59:701-7.

10 Rosemeyer B, Paulig R. Der Metakarpophalangealindex Orth Praxis 1980;23:89-91.

11 Hedtmann A, Fett H. Atlas und Lehrbuch der Schultersonographie. Stuttgart: Enke Verlag, 1988.

12 Jerosch J, Marquardt M, Winkelmann W. Der Stellenwert der Sonographie in der Beurteilung des glenohumeralen Gelenkes. Z Orthop 1990;128:41-5.

13 Norris TR. Diagnostic techniques for shoulder instability. In: Instructional course letter. American Academy of Orthopedic Surgeons. St Louis: CV Mosby, 1985

14 Pappas AM, Zawacki RM, McCarthy CF. Rehabilitation of the pitching shoulder. Am $\mathcal{F}$ Sports Med 1985;13:223-35.

15 Richardson AB, Jobe FW, Collins HR. The shoulder in competitive swimming. Am $\mathcal{f}$ Sports Med 1980;8:159-63.

16 Eggert S, Holzgraefe M. Die Kompressionsneuropathie des Nervus subscapularis bei Hochleistungsvolleyballern. Sportverl Sportschad 1993;7:136-42.

17 Pappas AM, Zawacki RM, Sullivan TJ. Biomechanics of baseball pitching A preliminary report. 1985;13:216-22.

18 Perry J. Muscle control of the shoulder. In: Rowe CR, ed. The shoulder. New York: Churchill Livingstone, 1988:17.

19 Gowan ID, Jobe FW, Tibone JE, Perry J, Moynes DR. A comparative electromyographic analysis of the shoulder comparative electromyographic analysis of the sho
during pitching. Am $\mathcal{F}$ Sports $M e d 1987 ; 15 \cdot 586-90$.

20 Burkhead Z, Rockwood CA. Treatment of instability of the shoulder with an exercise program. F Bone foint Surg Am 1992;74-A:890-6.

21 Jobe FW, Moynes DR. Delineation of diagnostic criteria and rehabilitation program for rotator cuff injuries. Am $\mathcal{f}$ Sports Med 1982;10:336-9. 